2. Schoof PH, Koch AD, Hazekamp MG, Waterbolk TW, Ebels T, Dion RA. Bovine jugular vein thrombosis in the Fontan circulation. J Thorac Cardiovasc Surg. 2002;124:1038-40.

3. Tiete AR, Sachweh S, Roemer U, KozlikFredmann R, Reuchart B, Daebritz SH. Right ventricular outflow tract reconstruction with the Contegra bovine jugular vein conduit: a word of caution. Ann Thorac Surg. 2004;77:2151-6.

4. Shebani SO, McGuirk S, Baghai M, Stickley J, DeGiovanni JV, Bu'Lock F, et al. Right ventricular outflow tract reconstruction using Contegra valved conduit: natural history and conduit performance under pressure. Eur J Cardiothorac Surg. 2006;29: 397-405.

5. Baslaim G. Bovine valved xenograft (Contegra) conduit in the extracardiac Fontan procedure: the preliminary experience. J Card Surg. 2008;23: 146-9.

doi:10.1016/j.jtcvs.2009.02.051

\section{LATE RUPTURE OF EXPANDED POLYTETRAFLUORO- ETHYLENE NEOCHORDAE USED FOR MITRAL VALVE REPAIR}

\section{To the Editor:}

In the February issue of the Journal, Farivar and colleagues ${ }^{1}$ described a case of late rupture of expanded polytetrafluoroethylene (ePTFE) neochordae after mitral valve repair. In the "Discussion," they state that there was only 1 previous case reported in the literature of ruptured neochordae, presented by Buttany and colleagues, ${ }^{2}$ suggesting their case as the second reported. This is not correct. In 2007, the Journal of Heart Valve Disease published our report of 2 cases of acute mitral regurgitation caused by ruptured ePTFE neochordae. ${ }^{3}$ Our patients presented with symptoms of acute heart failure caused by sudden rupture of the chordae, which was different from the rare clinical manifestations, hemolysis, and hematuria experienced by the patient reported by Farivar and colleagues.

We first used ePTFE routinely to correct ruptured or elongated chordae tendineae during the late 1980s and have since implanted it in more than 500 patients without a single known case of ePTFE failure necessitating reoperation, until these 2 late events occurred. After a thorough literature search regarding the possible mechanisms behind this unusual occurrence, we analyzed our histopathologic findings. We found that there was likely pannus formation and collagen infiltration through the porous structure that could account for progressive disruption before calcification ensued, which could be postulated as a form of repair/scarring.

In addition to the degenerative causes that could be responsible for the late rupture, we believe that the use of forceps and other metal instruments in the manipulation of the ePTFE could interrupt its electronegative charge and weaken the material. We currently avoid any kind of metallic manipulation.

\section{Gonçalo Coutinho, MD \\ Lina Carvalho, $M D, P h D$ \\ Manuel J. Antunes, MD, PhD, DSc \\ Center of Cardiothoracic Surgery \\ University Hospital Coimbra, Portugal}

\section{References}

1. Farivar RS, Shernan SK, Cohn LH. Late rupture of polytetrafluoroethylene neochordae after mitral valve repair. J Thorac Cardiovasc Surg. 2009; 137:504-6.

2. Buttany J, Collins MJ, David TE. Ruptured synthetic expanded polytetrafluoroethylene chordae tendineae. Cardiovasc Pathol. 2004;13:182-4.

3. Coutinho GF, Carvalho L, Antunes MJ. Acute mitral regurgitation due to ruptured $\mathrm{PTFE}$ neo-chordae. J Heart Valve Dis. 2007;16:278-81.

doi:10.1016/j.jtcvs.2009.02.050

\section{BIVENTRICULAR PACING} AFTER CARDIAC SURGERY

\section{To the Editor:}

We read with interest the article by Evonich and colleagues ${ }^{1}$ in the October issue of the Journal. They performed a randomized study of pacing modes ("normal care," synchronous atrial-right ventricular pacing, and synchronous atrial-biventricular pacing) in 40 patients with impaired left ventricular function after cardiac surgery. They included both a crossover study of acute hemodynamic variables early after operation (in 29 patients) and an assessment of clinical end points, such as intensive therapy unit and hospital stay and mortality. In contrast with experience in chronic heart failure, they showed no advantage to biventricular pacing in any area, although the trial was underpowered for the clinical end points.

They suggest this was the first randomized study in surgical patients but did not cite our 2005 publication. ${ }^{2}$ We performed a similar randomized crossover study, with hemodynamic assessment of different pacing modes in a similar number of patients (25) early after surgery. We demonstrated a clear advantage to atrial-left ventricular pacing and regard this modality as an important addition to the postoperative care of the compromised patient.

Closer analysis of the results in the article by Evonich and colleagues ${ }^{1}$ suggests that there is a serious error or that they too found an advantage but did not recognize it. In the second paragraph of the section titled "Hemodynamic Testing,' they state a statistically significant difference in stroke volume, cardiac output, and left ventricular stroke work index between AAI and atrial-right ventricular pacing. $B u t$, in Table 2, the values they refer to in the text are in the column under atrial-biventricular pacing pacing. If Table 2 is to be believed (and there is inconsistency in nomenclature, does AAI equate to "usual care"?), these investigators did see an advantage to biventricular pacing.

We believe biventricular pacing is of advantage to the postsurgical patient. Even if we are mistaken in our interpretation of this article, surgeons are left with 2 series of patients with contrasting results, perhaps because both have small numbers. This calls for a larger definitive study.

Michael Flynn, FRCS

John H. Dark, FRCS

Janet M. McComb, FRCP, MD

University of Newcastle upon Tyne United Kingdom 


\begin{abstract}
References
1. Evonich RF, Stephens JC, Merhi W, Dukkipati S, Tepe N, Shannon F, et al. The role of temporary biventricular pacing in the cardiac surgical patient with severely reduced left ventricular systolic function. J Thorac Cardiovasc Surg. 2008;136:915-21.

2. Flynn MJ, McComb JM, Dark JH. Temporary left ventricular pacing improve haemodynamic performance in patients requiring epicardial pacing post cardiac surgery. Eur J Cardiothorac Surg. 2005; 28:250-3.
\end{abstract}

doi:10.1016/j.jtcvs.2009.03.056

\section{PERCUTANEOUS AORTIC VALVE IMPLANTATION: WHAT DOES OVERSIZING MEAN?} To the Editor:

We read with interest the recent article by Litzler and colleagues ${ }^{1}$ in the Journal of Thoracic and Cardiovascular Surgery. The authors reported their first case of emergency surgical aortic valve replacement for severe acute aortic regurgitation after retrograde transfemoral Cribier-Edwards valve implantation.

We would like to comment on this instructive case report and ask for some clarifications:

When valved stent implantation is planned in a patient, accurate preprocedural determination of the aortic annulus size is of crucial importance. A prosthesis-aortic annulus mismatch may be responsible for valve migration or severe paravalvular leak if the chosen prosthesis is too small and for coronary obstruction or leaflet distortion if it is too large. ${ }^{2}$

The incidence of paravalvular leak has been shown to be dramatically high in previous studies. ${ }^{3,4}$ To reduce the incidence and severity of paravalvular leak, the oversizing technique (ie, the choice of a prosthesis size at least $2 \mathrm{~mm}$ more than that of the aortic annulus diameter as determined by transthoracic echocardiography [TTE]) has been proposed and proved to be effective. ${ }^{4}$

Nevertheless, several previous studies have shown that measurement of the aortic annulus diameter by TTE is inaccurate when compared with surgical sizing. ${ }^{5}$ TTE tends to underesti-

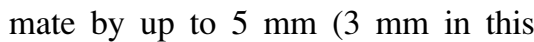
case report) the size of the aortic annulus. In the present case, the chosen size of the implanted valve was $23 \mathrm{~mm}$. The latter was supposed to be oversized based on the TTE measurements. The surgically implanted valve was also $23 \mathrm{~mm}$ based on the surgical measurements. Despite "oversizing" in this reported percutaneous valve implantation, severe paravalvular leak occurred, which means, in a sense, that this strategy has not solved this major problem at the present time.

We would like to ask the authors a few questions:

- What does "oversizing" mean for them in the choice of the implantable valve ? Is oversizing based on the TTE measurements of the aortic annulus diameter or is it based on the "true", aortic annulus diameter if the latter could be measured?

- Do they still rely on TTE for determination of the aortic annulus diameter or have they changed their imaging technique?

- Have they changed the magnitude of oversizing, based on this reported experience?

- If so, how effective is their new approach regarding the occurrence of paravalvular leak?

Optimal sizing of valved stents remains a critical issue with many implications on the post-procedural course. The readers of the Journal would greatly appreciate the answers to these "practical" questions from one of the most experienced teams in interventional aortic valve therapy.

$$
\begin{array}{r}
\text { Rachid Zegdi, } M D, P h D^{a, b} \\
\text { Paul Achouh, } M D, P h D^{b} \\
\text { Didier Blanchard, } M D^{c} \\
\text { Antoine Lafont, MD, } P h D^{a, c} \\
\text { Jean-Noël Fabiani, } M D^{a, b} \\
{ }^{a} \text { Université René Descartes } \\
\text { Paris } V, \text { France } \\
{ }^{b} \text { Assistance Publique-Hôpitaux de } \\
\text { Paris, AP-HP } \\
\text { Service de Chirurgie } \\
\text { Cardiovasculaire }
\end{array}
$$

Hôpital Européen Georges Pompidou

Paris, France

${ }^{c}$ Assistance Publique-Hôpitaux de

Paris, AP-HP

Service de Cardiologie

Hôpital Européen Georges Pompidou

Paris, France

\section{References}

1. Litzler P-Y, Cribier A, Zajarias A, Comte D, Eltchaninoff $\mathrm{H}$, Tron C, et al. Surgical aortic valve replacement after percutaneous aortic valve implantation: what have we learned? J Thorac Cardiovasc Surg. 2008;136:697-701.

2. Zegdi R, Ciobotaru V, Noghin M, Sleilaty G, Lafont A, Latremouille $\mathrm{C}$, et al. Is it reasonable to treat all calcified aortic valves with a valved stent? Results from a human anatomic study. J Am Coll Cardiol. 2008;51:579-84.

3. Webb JG, Chandavimol M, Thompson CR, Ricci DR, Carere RG, Munt BI, et al. Percutaneous aortic valve implantation retrograde from the femoral artery. Circulation. 2006;113:842-50.

4. Cribier A, Eltchaninoff $\mathrm{H}$, Tron $\mathrm{C}$, Bauer $\mathrm{F}$, Agatiello C, Nercolini D, et al. Treatment of calcific aortic stenosis with the percutaneous heart valve. Mid-term follow-up from the initial feasibility studies: the French experience. J Am Coll Cardiol. 2006; 47:1214-23.

5. Mackay A, Been M, Rodrigues E, Murchison J, De Bono DP. Preoperative prediction of prosthesis size using cross sectional echocardiography in patients requiring aortic valve replacement. Br Heart J. 1985;53:507-9

doi:10.1016/j.jtcvs.2008.11.072

\section{PROGNOSTIC SIGNIFICANCE OF VISCERAL PLEURAL INVASION AND TUMOR SIZE IN NON-SMALL CELL LUNG CANCER}

\section{To the Editor:}

We read with great interest the article by Shimizu and colleagues ${ }^{1}$ published in the July 2005 issue of the Journal. They found that visceral pleural invasion (VPI) is a significant poor prognostic factor of non-small cell lung cancer (NSCLC), regardless of N status. Stage I NSCLC has been subdivided into IA (T1NOM0) and IB (T2NOM0) based on tumor size ( $3 \mathrm{~cm}$ as a cutoff value) and non-size-based T2 descriptors (including VPI, hilar atelectasis, and obstructive pneumonitis). ${ }^{2}$ Although a poor prognostic effect of VPI has generally been reported, its prognostic value for survival has remained controversial. ${ }^{3,4}$ 